of the Fourth International Seminar, c/o Waters Associates, Inc., 61 Fountain Street, Framingham, Massachusetts 01701 .

A conference on "Frequency Generation and Contrcl for Radio Systems" will be held at the Institution of Electrical Engineers during May 22-24. The aim of the conference is to review the developments in techniques of frequency generation, synthesis, control and distribution as applied to radio communications, navigation and radar systems. Further information can be obtained from the Conference Section, Institution of Electrical Enginoers, Savoy Place, London, W.C.2.

AN international congress on "Sulphur Oxides" will be held in the University of Toulouse during May 22-26. Further information can be obtained from the Secrétariat du Congrès, Association des Ingénieurs du Génie Chimique, Institut du Génie Chimique, Chemin de la Loge-Empalot, 31-Toulouse.

Corrigendum. In the article entitled "Activity of Ribosomal Phosphodiesterase in a Protozoan", by L. H. Lazarus and O. H. Scherbaum (Nature, 213, 887; 1967), the following should be added to the end of the last sentence of para. 5: ", either as magnesium and/or calcium ions.". Lines 10 and 11 of para. 6 should read: ". . . This ribosome-bound enzymo with its high $p \mathrm{H}$ for optimum activity is . ..". In line 3 of the legend to Table 1 "magnesium chlorate" should read "magnesium chloride". The fifth line of the legend to Table 2 should be "... tryptophan plus potassium chloride relative to potassium chloride alone.". In the first column in Table 2 the word "Plus" should be deleted from entries 5-8. The last two entries in this column should then be moved under entry 8.

Erratum. In the article entitled "Preliminary Observation on the Lipids of Bovine Retinal Outer Segment Disks" by S. Fleischer and D. G. McConnell (Nature, 212,
$1366 ; 1966)$, the second line of the third paragraph should read "resolved into six fractions. ....".

Erratum. In the article "Reduction of Methaemoglobin in Haemoglobin Samples using Gel Filtration for Continuous Removal of Reaction Products" by H. B. F. Dixon and R. McIntosh (Nature, 213, 399; 1967), second paragraph, line 5, "12 mg sodium dithionite" was incorrectly given as " $12 \mathrm{ml}$. ...".

\section{CORRESPONDENCE}

\section{Asbestos in the Lungs}

SIR,-The first paragraph of this review (Nature, 213 , $855 ; 1967)$ states that mesotheliomas of the pleura and peritoneum only occur in association with exposure to crocidolite asbestos dust. This statement is not in accordance with our present knowledge. These tumours have occurred in people in whom no evidence of exposure to asbestos dust was established. Furthermore, crocidolite is not necessarily the only type of asbestos implicated. Investigations in the United States ${ }^{1,2}$ have indicated that other types of asbestos may be involved. The international investigations which are described later in your article are planned to measure the absolute and relative risk of tumour development with all types of fibres.

Yours, etc.,

J. C. Gulson

J. C. WAGNER

MRC Pneumoconiosis Research Unit,

Llandough Hospital,

Penarth, Glamorgan.

${ }^{2}$ Selikoff, Irving J., Churg, Jacob, and Hammond, E. Cuyler, Nezv Ling. J. Med., 272, $5 \ddot{\theta \theta 0}(1965)$. O'Donnel, Ward M., Mann, Richard H., and Grosh, John L., Cancer, 19 ,
1143 (1966).

\title{
THE NIGHT SKY IN APRIL
}

All times are in Universal Time

\begin{tabular}{|c|c|c|c|}
\hline \multicolumn{2}{|c|}{ MOON } & \multicolumn{2}{|c|}{ CONJUKCTIONS WITH THE MOON } \\
\hline $\begin{array}{l}\text { New Moon } \\
\text { Full Moon }\end{array}$ & $\begin{array}{r}9 \mathrm{~d} 22 \mathrm{~h} \\
24 \mathrm{~d} 12 \mathrm{~h}\end{array}$ & $\begin{array}{l}\text { Venus } \\
\text { Mars } \\
\text { Jupiter } \\
\text { Saturn }\end{array}$ & $\begin{array}{l}\text { 13d } 06 \mathrm{~h}, 0.8^{\circ} \mathrm{s} . \\
23 \mathrm{~d} 17 \mathrm{~h}, 0^{\circ} 4^{\circ} \mathrm{N} . \\
17 \mathrm{~d} 16 \mathrm{~h}, 5^{\circ} \mathrm{S} . \\
8 \mathrm{~d} 15 \mathrm{~h}, 0.8^{\circ} \mathrm{N} .\end{array}$ \\
\hline
\end{tabular}

Planets

\begin{tabular}{|c|c|c|c|c|c|c|c|}
\hline \multicolumn{8}{|c|}{ Times of rising $(R)$ and setting $(S)$ during the month } \\
\hline Name & $R / S$ & Beginning & Middle & Find & Mag. & $D_{g}\left(10^{6}\right.$ miles $)$ & Zodiacal position \\
\hline Mercury & - & \multicolumn{4}{|c|}{ Unfavourable for observation } & 102 & Pisces \\
\hline Venus & $S$ & $21 \mathrm{~h} 45 \mathrm{~m}$ & $22 \mathrm{~h} 30 \mathrm{~m}$ & $23 \mathrm{~h} 20 \mathrm{~m}$ & -3.5 & 113 & Taurus \\
\hline Mars & $R / S$ & $20 \mathrm{~h} \mathrm{00 \textrm {m }}(R)$ & $18 \mathrm{~h} 40 \mathrm{~m}(R)$ & $4 \mathrm{~h} 10 \mathrm{~m}(S)$ & $-1 \cdot 3$ & 56 & Virgo \\
\hline Jupiter & $s$ & $3 \mathrm{~h} 20 \mathrm{~m}$ & $2 \mathrm{~h} 25 \mathrm{~m}$ & $1 \mathrm{~h} 30 \mathrm{~m}$ & -1.7 & 481 & Gemini \\
\hline Saturn & -. & \multicolumn{4}{|c|}{ Unfavourable for observation } & 970 & Cetus \\
\hline
\end{tabular}

$D_{g}$ is the distance of planet from the Earth on the 15th of the month.

Occultations of Stars Brighter than Magnitude +6 at Greenwich

$\begin{array}{lccc}\text { Star } & R / D & \text { Time } & \text { Mag. } \\ 47 \mathrm{Gem} & D & 17 \mathrm{~d} 00 \mathrm{~h} 13 \cdot 3 \mathrm{~m} & +5 \cdot 6 \\ \omega \mathrm{Cnc} & D & 17 \mathrm{~d} 19 \mathrm{~h} 45 \cdot 3 \mathrm{~m} & +5 \cdot 9\end{array}$

MaTEORS

( $D$ disappearance; $R$ reappearance)

$\begin{array}{lcccc}\text { Name } & \text { Active period } & \text { Date of maximum } & \text { Radiant } & \text { Remarks } \\ \text { Lyrids } & 19 \mathrm{~d}-23 \mathrm{~d} & 22 \mathrm{~d} & 271^{\circ} \mathrm{R} . \mathrm{A} .+33^{\circ} \text { Dec. } & \text { Unfavourable }\end{array}$

Other Phenomena

8d 15h, Saturn occulted by the Moon, visible in S. America.

13d $06 \mathrm{~h}$, Venus occulted by the Moon, visible in N.E. Europe and Asia.

23d 17h, Mars occulted by the Moon, visible in Central and East Africa, s. Australia.

$24 \mathrm{~d} 12 \mathrm{~h}$, Total eclipse of the Moon, Moon enters umbra $10 \mathrm{~h} 25 \mathrm{~m}$, visible in the Americas, Asia, Australasia.

$\begin{array}{ll}\text { Total eclipse begins } & 11 \mathrm{~h} 28 \mathrm{~m} \\ \text { Mid eclipse } & 12 \mathrm{~h} 07 \mathrm{~m} \\ \text { Total eclipse ends } & 12 \mathrm{~h} 46 \mathrm{~m} \\ \text { Moon leaves umbra } & 13 \mathrm{~h} 49 \mathrm{~m}\end{array}$ 